\title{
Вмנ Global Health Village-level climate and weather variability, mediated by village-level crop yield, is associated with linear growth in children in Uganda
}

\author{
Paddy Ssentongo (D) , ${ }^{1}$ Djibril M Ba, ${ }^{1}$ Claudio Fronterre, ${ }^{2}$ Vernon M Chinchilli ${ }^{1}$
}

To cite: Ssentongo P, Ba DM, Fronterre C, et al. Village-level climate and weather variability, mediated by village-level crop yield, is associated with linear growth in children in Uganda. BMJ Global Health 2020;5:e002696. doi:10.1136/ bmjgh-2020-002696

Handling editor Seye Abimbola

- Additional material is published online only. To view please visit the journal online (http://dx.doi.org/10.1136/ bmjgh-2020-002696).

Received 20 April 2020 Revised 26 August 2020 Accepted 27 August 2020

A Check for updates

(C) Author(s) (or their employer(s)) 2020. Re-use permitted under CC BY-NC. No commercial re-use. See rights and permissions. Published by BMJ.

${ }^{1}$ Public Health Science, Penn State Health Milton S Hershey Medical Center, Hershey, Pennsylvania, USA

${ }^{2}$ Centre for Health Informatics, Computing and Statistics, Lancaster University, Lancaster, UK

\section{Correspondence to} Dr Paddy Ssentongo; pssentongo@pennstatehealth. psu.edu

\section{ABSTRACT}

Introduction To investigate total annual precipitation, precipitation anomaly and aridity index in relation to linear growth in children under 5 in Uganda and quantify the mediating role of crop yield.

Methods We analysed data of 5219 children under 5 years of age who participated in the 2016 Uganda Demographic and Health Survey. Annual crop yield in kilograms per hectare for 42 crops at a $0.1^{\circ}(\sim 10 \mathrm{~km}$ at the equator) spatial resolution square grid was obtained from the International Food Policy Research Institute. Normalised rainfall anomaly and total precipitation were derived from the African Rainfall Estimation Algorithm Version 2 product. Linear regression models were used to associate total annual precipitation and anomalies with height-for-age z-scores and to explore the mediating role of crop yield qualitatively. The intervening effects were quantitatively estimated by causal mediation models. Results Twenty-nine per cent of children were stunted (95\% Cl $28 \%$ to $31 \%$ ). After adjusting for major covariates, higher total annual precipitation was significantly associated with increasing height-for-age z-scores. At the mean, an increase of 1 standard deviation in local annual rainfall was associated with a 0.07-point higher z-score. Aridity index and precipitation anomaly were not associated with height-for-age z scores in altitudeadjusted models. Crop yields of nuts, seeds, cereals and pulses were significant mediating factors. For instance, $38 \%$ of the association between total annual precipitation with height-for-age z-scores can be attributed to the yield of sesame seeds.

Conclusions Higher total annual precipitation at the village-level was significantly associated with higher height-for-age z-scores among children in Uganda. This association can be partially explained by higher crop yield, especially from seeds and nuts. This study suggests that more attention should be paid to villages with lower annual rainfall amounts to improve water availability for agriculture.

\section{INTRODUCTION}

Globally, one in nine people are undernourished, leading to nearly half of deaths among children under-5 years of age. ${ }^{12}$ One of the
Summary box

What is already known?

- Previous analysis using coarse spatial climatic and weather variables found a significant linear relationship of precipitation and climatic shocks with child undernutrition in Uganda.

- However, whether a variety of crop yields causally mediates this association is unknown.

What are the new findings?

- Using causal mediation analysis, this is the first study to explore the combination of climate/ weather/environmental conditions and village-level crop yield (42 different types of crops) and how these factors affect child nutritional outcomes.

- Ours is the first study to explore the types of crop yield of 42 types of rainfall-sensitive crops at $10 \mathrm{~km}$ spatial resolution and their effect on child linear growth in Uganda.

What do the new findings imply?

- Our causal mediation modelling approach and output should be used to target interventions to children and to villages at highest risk of climate-driven undernutrition.

- Our findings reveal types of nutritional crops that are rainfall-sensitive and crop yield that display more substantial effects on linear growth.

manifestations of undernutrition is stunting, in-which children exhibit a height-for-age $\mathrm{z}$ score of $<2$ standard deviation (SD) below the international median value of well-nourished children using WHO normative growth standards. ${ }^{3}$ In Uganda, the prevalence of stunting has remained consistently high over the past decades, where approximately $30 \%$ of the children under 5 years are stunted. ${ }^{45}$ Stunting has been shown to be sensitive to climatic shocks and weather variations. ${ }^{6-9}$ Due to the rising temperatures resulting from climate change and extreme rainfall anomalies, WHO and the fifth Assessment Report of 
the Intergovernmental Panel on Climate Change have viewed malnutrition as one of the five largest adverse health impacts of climate change. ${ }^{10}$ However, empirical evidence causally connecting climate change or weather variability to undernutrition in rainfed-agricultural areas of low-income and middle-income countries, is scarce.

In Uganda, precipitation shortfalls are becoming more frequent. In a recent study, Uganda rainfall at the village level was found to be declining by $12 \%$ for the past 34 years. ${ }^{11}$ Spatiotemporally, these decreases were greatest in agricultural regions of central and western Uganda. In addition, rising temperatures, which increase the evapotranspiration rates, cause long-term precipitation deficits leading to arid conditions even in the areas of adequate rainfall. Uganda's dependence on rainfed agriculture leads to high vulnerability to both short-term and long-term fluctuations in rainfall amount. The rainfall in Uganda is largely determined by the passage of the intertropical convergence zone (ITCZ) modulated by the complex topography and the presence of the lakes. ${ }^{12}$ Southern Uganda experiences two distinct rainfall seasons (March to May and September to November), coinciding with the northward and southward passage of the ITCZ. These two seasons merge into one in the north of the country, lasting from April to October. Uganda, being a landlocked country in Eastern Africa, depends on the local agricultural production and subsistence farming. As a result, the typical Ugandan diet lacks nutritional diversity, as many households feed on starchy roots and tubers such as cassava and sweet potatoes, and nutrient-deprived plantains. ${ }^{13}$

Currently, a dearth of empirical evidence exists linking precipitation amount, anomaly and aridity index to nutrition outcomes in Uganda. In 2017, Shively used regression methods to explore the impact of district-level precipitation and undernutrition using the 2011 Uganda Demographic and Health Survey (UDHS). ${ }^{7} \mathrm{He}$ concluded that a small variation of child nutrition outcomes could be explained by precipitation. However, the analysis of district-level rainfall introduced a large bias in the estimates due to the high heterogeneity of precipitation amount both temporally and spatially. ${ }^{11}$ We circumvent this obstacle by employing village level rainfall measured at $10 \mathrm{~km}$ regular grid. Furthermore, previous studies failed to investigate the mediating potential of crop yield in the association of weather and climatic variability with child growth. We improve on previous work by using rigorous statistical methods of causal mediation analysis to explore whether the association between climatic and weather precipitation and child growth is casually mediated by the agricultural yield of over 40 specific crops, including cereals, roots, legumes, seeds oil and the staple foods in Uganda. We confront the challenges of spatial granularity by incorporating a wide range of remotesensing data from the National Oceanic and Atmospheric Administration (NOAA), the National Aeronautics and Space Administration and International Food Policy Research Institute (IFPRI), a dataset at very small spatial scales of $\sim 1$ to $10 \mathrm{~km}$, equivalent to the village level in Uganda. We hypothesised that precipitation amount, anomalies and aridity index in Uganda influence various crop yields, affecting food availability and linear growth in children ages 5 years and under.

\section{METHODS}

\section{Data sources and participants}

Data were from the latest (2016) UDHS. The data were collected between 20 June 2015 and 16 December 2016, by the Uganda Bureau of Statistics in collaboration with the Ministry of Health and coordinated by ICF International in Rockville, Maryland, USA. ${ }^{14}$ The United States Agency for International for Development, Government of Uganda, UNICEF and the United Nations Population Fund provided financial support to carry out the UDHS programme. The survey collected nationally representative health data to monitor and evaluate population health and nutrition programmes. The details of sampling methods are discussed in detail elsewhere. ${ }^{14}$ In summary, data collection involved a multistage stratified sampling design. First, Uganda was divided into 15 regions. Within these regions, populations were stratified by urban and rural areas of residence. A random selection of 696 enumeration areas (EAs) or primary sampling units (PSUs) was drawn within these stratified areas. In Uganda, an EA is a geographical area that covers an average of 130 households. PSUs were selected based on a probability that was proportional to the population size. Next, in the second stage of sampling, all households within a PSU were listed from the most recent population census (2014), and $\sim 30$ households per PSU were randomly selected for an interview with the use of equal probability systematic sampling. In total, a representative sample of 20880 households were selected for the 2016 UDHS. For each sampled household, household members were listed, and women who were eligible for a more-detailed interview were identified. These women were between the ages of 15 and 49 years. Height and weight information were also collected from eligible women and men, as well as children of ages $0-59$ months.

\section{Assessment of undernutrition status}

Data were collected by field workers after receiving intensive training lasting at least 4 weeks by the Ugandan Bureau of Statistics. The training included lectures, demonstrations of biomarker measurement or testing procedures, field practice with children at a health clinic and standardisation of height and weight measurements. Children aged 24 months and younger had their length measured in a recumbent position, but children above 2 years old had their height measured while standing. The length was measured with the portable Harpenden Infantometer (range 30-110 cm, with digit counter readings precise to $1 \mathrm{~mm}$ ), and height was measured using the Harpenden Portable Stadiometer (range 65-206 cm, digit counter reading precisely to $1 \mathrm{~mm}$ ). The z-scores for 
length/height-for-age were provided in the UDHS data calculated using the 2006 WHO Child Growth Standards. ${ }^{3}$ A child was stunted if he/she exhibited a z-score $<-2$ SD. Z-scores measure the dispersion of the child health indicator as SD around a reference. A total of 5219 children had height-to-age $\mathrm{Z}$ score (HAZ) information available. Written informed consent was obtained from each participant, their parents or guardians before the survey. The DHS Programme permitted the authors to use the data. The data are entirely anonymous; therefore, the authors did not seek further ethical clearance.

\section{Assessment of predictors and mediators}

Crop yield at $10 \times 10 \mathrm{Km}$ grid-cell resolution

We obtained crop yield data from the Spatial Production Allocation Model 2010 V.1.0 (SPAM 2010 V.1.0), a highresolution global crop production dataset from IFPRI. ${ }^{15}$ IFPRI is a member of the Consultative Group for International Agricultural Research's Consortium of International Agricultural Research Centres. SPAM provides key crop production indicators, including area, production, and yield, for 42 crops-disaggregated at the input levels (eg, irrigated/rainfed and high/low-input) of $10 \mathrm{~km}$ square grids globally. We used tiff files with values for yield ( $\mathrm{kg} / \mathrm{ha})$ for each crop and technology. Eighty per cent of Uganda's population is dependent on rainfed agriculture. Therefore, we explored agricultural yield of rainfed crops. A list of 42 crops as listed in the SPAM 2010 dataset is given in online supplemental table 1.

\section{Local total annual precipitation}

Rainfall data (in millimetres) were obtained from the African Rainfall Estimation Algorithm V.2 (RFE 2.0) product. ${ }^{16}$ Rainfall data are daily gridded, satellite-based precipitation estimates from the NOAA produced at a spatial resolution of $0.1^{\circ} \times 0.1^{\circ}$. RFE 2.0 combines satellite thermal infrared (TIR) data from Meteosat with passive microwave data from the advanced microwave sounding unit and special sensor microwave imager satellite instruments and Global Telecommunication System rain gauge data. Initial rainfall estimates are calculated from the TIR data using the Goddard Earth Observing System Precipitation Index.${ }^{17}$ We calculated the total annual precipitation for 2010. We chose 2010 as the median of the crop yield data, using data between 2009 and 2011. The amount of precipitation in a location affects the kind of crops grown and what livelihood systems people undertake. Areas that experience unusually high or low levels of annual precipitation are particularly sensitive to seasonal extremes.

\section{Local annual precipitation anomaly}

Annual precipitation anomaly is calculated as $a_{i t}=\left(x_{i t}-\bar{x}_{i t}\right.$ ) / $\sigma_{i t}$ where $a_{i t}$ is the precipitation anomaly at location $i$ in year $t, x_{i t}$ is the current precipitation at location $i$ in year $t . \bar{x}_{i t}$ is the annual average rainfall for location $i$ in year $t$ calculated across all years observed, and $\sigma$ is the calculated SD of observed annual precipitation for location $i$ in year $t$ across all years observed. We used the NOAA RFE2.0 daily rainfall data from the climate prediction centre from 1 January 2001 to January 2012. We needed the whole 12 years of data in order to detect rainfall anomalies. The 2010 normalised precipitation anomalies were calculated as the 2010 total precipitation minus the average total precipitation for the 2001-2012 period, divided by the SD of the 2001-2012 precipitation.

\section{Local Aridity Index}

To account for the long-term water availability at a child's location, we used the Global Aridity Index that provides high-resolution (30 arcs) raster climate data for the 1970-2000 period. ${ }^{18}$ The Global Aridity Index is the ratio between mean annual precipitation and mean annual reference evapotranspiration, based on the implementation of the Penman-Monteith evapotranspiration equation for a reference crop and using the WorldClim 2.0 data. ${ }^{19}$ The aridity index indicates rainfall over vegetation water demand (aggregated on an annual basis), and its value thus increases under more humid conditions and decreases with more arid conditions.

\section{Statistical analyses}

\section{Empirical strategy}

Our empirical goal was to decompose the total effects in the HAZ due to the climatic variables into the direct effects acting through the climatic/weather variables and the indirect effects through the mediators, crop yield (figure 1). We used the standard mediation model that includes multiple linear regression models which take the form ${ }^{20}$ :

$$
\begin{gathered}
M=\beta_{0}+X \beta_{1}+\varepsilon \\
Y=\theta_{0}+X \theta_{1}+M \theta_{2}+\delta
\end{gathered}
$$

where $M$ is the mediating variable (crop yield), $X$ is a vector of explanatory and confounding variables, $\beta_{1}$ and $\theta_{1}$ are vectors of parameters to be estimated, $Y$ is heightfor-age $\mathrm{z}$ score, and $\varepsilon$ and $\delta$ are error terms.

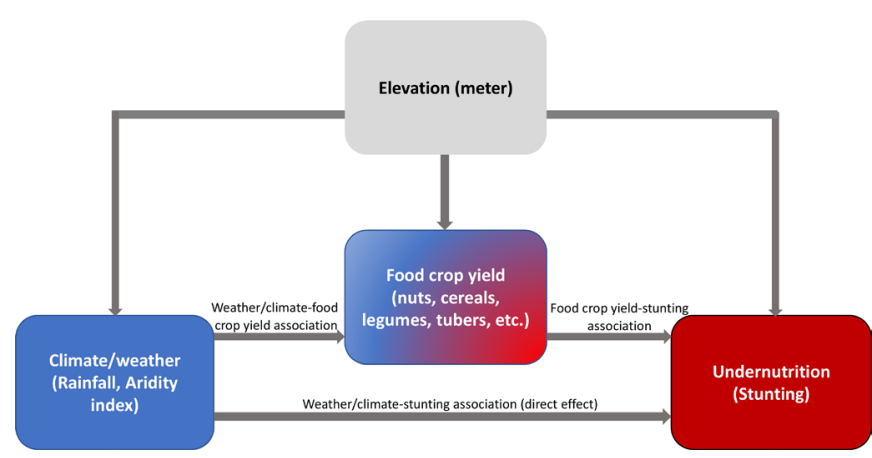

Figure 1 Conceptual framework of causal mediation model for the association of climate/weather and nutrition outcome. The effect of climate/weather on nutrition outcomes acting through food crop yield is referred to as the indirect effect. Remaining effect in the relationship between climate/weather and nutritional outcome is referred to as the direct effect. Elevation/altitude is a known confounding factor in the relationship between climate/weather and stunting. 


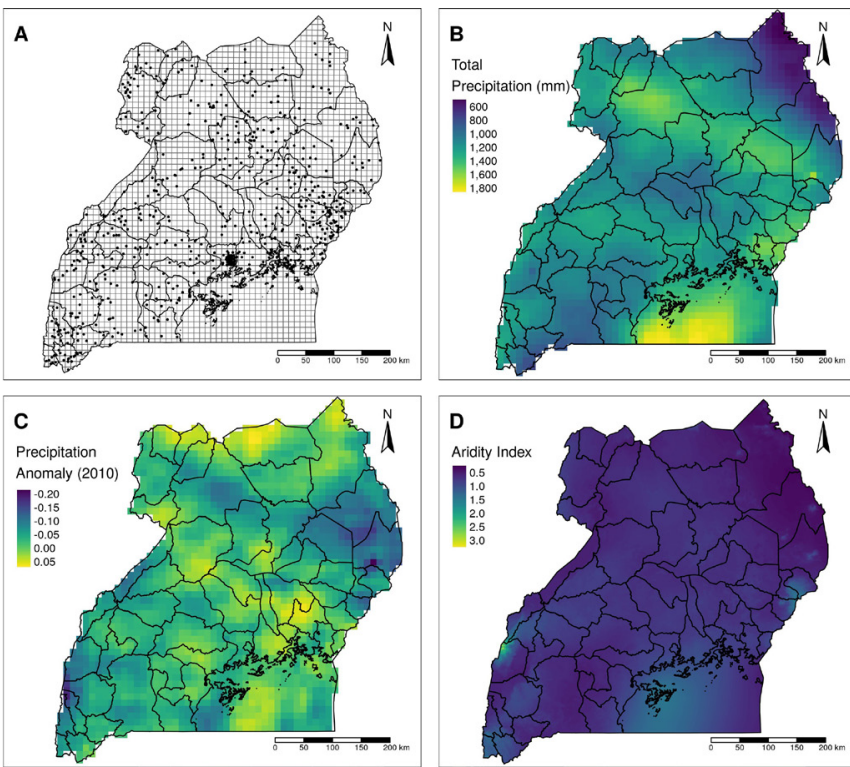

Figure 2 Survey participants, climatic and environmental factors: Spatial distribution of study participants on a $10 \mathrm{~km}$ grid square (A), 2010 total rainfall (B), precipitation anomaly, z-scores (C) and aridity index (D). Aridity Index values increase for more humid conditions, and decrease with more arid conditions. Generalised climate classification scheme for aridity index values is as follows: $<0.03$ hyperarid; $0.03-0.2$ arid; 0.2-0.5 semiarid; 0.5-0.65 dry subhumid; >0.65 humid.

Inserting the linear model for $\mathrm{M}$ into the linear model for $\mathrm{Y}$ yields

$$
Y=\left(\theta_{0}+\theta_{2} \beta_{0}\right)+X\left(\theta_{1}+\theta_{2} \beta_{1}\right)+\left(\theta_{2} \varepsilon+\delta\right)
$$

$\theta_{1}$ and $\theta_{2} \beta_{1}$ represent the direct and indirect effects, respectively, of the exposure on the outcome.

Among 5253 participants under 5 years in the 2016 UDHS survey, 34 individuals were excluded due to the missing HAZ values. Thus, the effective sample size for this report is 5219. Summary statistics of the demographics were calculated as mean (SD) and proportions. Linear regression models were used to assess the impact of climatic variables on HAZ. Initially, climatic variables were included in the models individually; that is, only one climatic variable entered the model as the independent variable to investigate the relationship between climatic variables and HAZ. Both unadjusted and major demographic covariates, including age, sex, were fitted in an adjusted model. We included total annual precipitation, precipitation anomaly for 2010 , aridity index and altitude (figure 2) in the same model to adjust for each other.

To explore the potential mediating role of annual crop yield in the association between climatic variables and child growth indictor, we pursued the following steps. First, we selected crops that had a significant association with height-for-age $\mathrm{z}$ scores. For the association of the 42 crops and height-for-age $\mathrm{z}$ scores, we first estimated the model using the Least Absolute Shrinkage and Selection Operator (LASSO) method. ${ }^{21}$ This method performs regularisation by penalising the size of the model coefficients to prevent overfitting and facilitates variable selection by shrinking some of the model coefficients to zero. ${ }^{21}$ The LASSO method involves recasting the regression problem as a convex optimisation, which simplifies model estimation. ${ }^{22}$ Crops with non-zero coefficients from the LASSO method were considered to be included in the causal mediation analysis as mediators (online supplemental table 2).

Second, selected crops were further adjusted in the models one at a time. The differences due to the additional adjustment of the potential mediating factors were used to elucidate the mediating role of these crop yield-related factors qualitatively. Finally, an R package, Mediation ${ }^{23}$ was used to estimate the mediating effects quantitatively, and direct effects of various crops yield in the association between annual precipitation and HAZ. The R-based (V.3.1.0) Mediation package estimated the confidence intervals using the bootstrap method with 1000 resamples, with a two-sided $\mathrm{p}<0.05$ indicating statistical significance.

\section{RESULTS}

\section{Demographic characteristics of the study population, a} summary of crop yield, weather and climatic variables

The demographic characteristics of the study population are shown in table 1 . The final study sample consisted of 5219 children under the age of 5 years. The participants' mean (SD) age was 29.4 (17.1) months, with 50\% male. On average, the participant's height-for-age z-score was -1.23 (1.48), and $29 \%$ were stunted (95\% CI $28 \%$ to $31 \%$ ). Thirty per cent tested positive for malaria parasite by rapid diagnostic test, $50 \%$ had taken deworming medication in the last 6 months, $83 \%$ lived in rural locations. About $50 \%$ of the children lived in households in the lowest and second lowest wealth index quintiles. Two-thirds of the children's mothers had less than a high school education. Spatial distribution of 42 crops is shown in figure 3. Uganda's five major food commodities (staple food) are plantains (matooke), cassava, maize, sweet potatoes and millet. Their 2010 mean annual yield in kilograms/hectare were 3492, 4430, 2994, 3850 and 1781, respectively. Among the legumes, soybeans and groundnuts had the highest yield of $639 \mathrm{~kg} / \mathrm{ha}$ and $627 \mathrm{~kg} / \mathrm{ha}$, respectively. Historically, over $80 \%$ of Uganda's export crops (also known as cash-crops) are cotton, coffee, tobacco and tea. Mean yield $(\mathrm{kg} / \mathrm{ha})$ of these exports were 652, (293 and 93 for Robusta and Arabica coffees, respectively), 1066 and 1566, respectively (online supplemental table 1). The mean (SD) of annual precipitation, precipitation anomaly, aridity index and elevation were $1214(170) \mathrm{mm},-0.03$ (0.04), 0.73 (0.15) and 1191 (232) m, respectively.

\section{Association between climatic variables and HAZ}

The associations between increases in climatic and weather variables and HAZ are presented in table 2 . The regression coefficient $(\beta)$, standard error (SE) and $p$ value from both the unadjusted model and various covariates 
Table 1 Demographic characteristics of the study population, a summary of crop yield, weather and climatic variables

\begin{tabular}{ll}
\hline Variable $(\mathbf{n}=\mathbf{5 2 1 9})$ & Mean \pm SD or $\mathbf{N}(\%)$ \\
\hline Child factors & \\
\hline Age, month & $29 \pm 17$ \\
\hline Male sex & $2586(50)$ \\
\hline Height-for-age z-scores & $-1.23 \pm 1.48$ \\
\hline Stunted & $1529(29)$ \\
Malaria positive & $1557(30)$ \\
\hline Deworming medication in the past & $2593(50)$ \\
6 months & \\
\hline
\end{tabular}

Household factors

\section{Wealth index quintiles}

\begin{tabular}{|ll}
\hline Lowest & $1359(26)$ \\
\hline Second & $1112(21)$ \\
\hline Fourth & $1047(20)$ \\
\hline Highest & $950(18)$ \\
\hline Rural residence & $751(14)$ \\
\hline
\end{tabular}

Maternal factors

Maternal education

Less than high school 490 (67)

High school 839 (16)

Greater than high school 242 (5)

Missing

$648(12)$

Crop yield (kg/ha)

Beans $440 \pm 350$

Cassava

$4430 \pm 3131$

Chickpeas

$55 \pm 316$

Groundnuts

$627 \pm 474$

Maize

$2994 \pm 1984$

Plantains (Matooke)

$3492 \pm 4539$

Rice

$584 \pm 927$

Sesame seed

$422 \pm 540$

Small millet

$1781 \pm 1726$

Sorghum

$985 \pm 576$

Soybean

$639 \pm 618$

Sunflower

$1024.04 \pm 17$

Sweet potatoes

$3849.62 \pm 17$

Temperate fruit

$5029 \pm 2719$

Tropical fruit

$6717 \pm 5625$

Vegetables

$4168 \pm 2466$

\begin{tabular}{ll} 
Climate/weather variables & \\
\hline 2010 total precipitation $(\mathrm{mm})$ & $1214 \pm 170$ \\
2010 precipitation anomaly z- & $-0.03 \pm 0.04$ \\
scores & \\
Aridity Index & $0.73 \pm 0.15$ \\
Elevation (metres) & $1191 \pm 232$
\end{tabular}

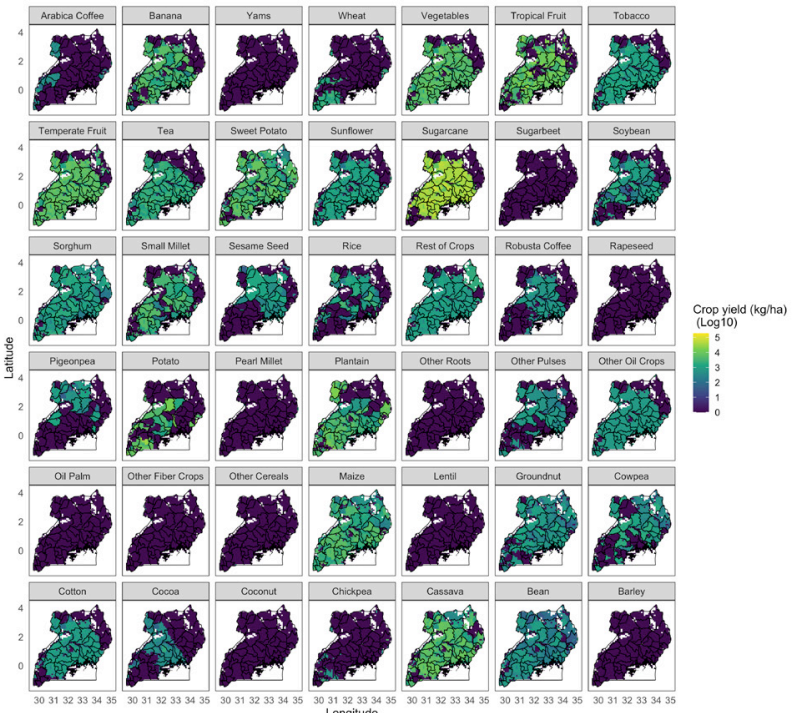

Figure 3 Spatial distribution of the yield of the 42 crops $(\mathrm{kg} /$ ha) explored in this study.

adjusted models (model $1-$ model $1 \mathrm{~h}$ ) shows the impacts of climatic variables on HAZ measurements separately. In the unadjusted models, increased annual village-level total precipitation and positive precipitation anomaly (increase in precipitation) is consistently associated with increased HAZ. In contrast, high aridity index (humid) was associated with decreased HAZ. After controlling for the demographic variables and elevation (model 1), the significance and the magnitude of the $\beta$ values of the associations between annual precipitation total and HAZ remained the same. For example, with a 1 SD increase $(170 \mathrm{~mm})$ in annual rainfall, the associated increase in HAZ remained 0.07 ( $\mathrm{SE}=0.02, \mathrm{p}=0.006)$. However, the same adjustment of major covariates completely diminished any significant association of precipitation anomaly and aridity index with HAZ. Although no statistically significant association of precipitation anomaly and aridity index with HAZ was found in the adjusted models, there is a consistent trend that positive rainfall anomaly and increasing aridity index (a gradient increasing from arid to humid location) is positively related to HAZ.

\section{Mediating effect of crop yield}

Because total annual precipitation was significantly associated with crop yield (eg, a $100 \mathrm{~mm}$ increase in annual precipitation, is associated with approximately a $200 \mathrm{~kg} /$ ha increase in sweet potato yield), we further investigated the potential mediating role of crop yield in the association between annual precipitation and HAZ. The relationships between annual precipitation and HAZ, after additional adjustment of crop yield, are shown in models $1 \mathrm{a}-1 \mathrm{~h}$ of table 2 , respectively, for the adjustments of sweet potatoes, groundnuts, sesame seeds, chickpea, others pulses, rice, maize and plantains (Matooke). Only the crops that were positively associated with HAZ by using the LASSO method were considered potential mediator. These crops included legumes, cereals, roots 
Table 2 Regression coefficients (SE) and $p$ values in the association between climatic variables and height-for-age $z$ scores

\begin{tabular}{|c|c|c|c|c|c|c|c|c|c|c|}
\hline Variable & $\begin{array}{l}\text { Unadjusted } \\
\beta(\mathrm{SE})\end{array}$ & $\begin{array}{l}\text { Model } 1 \\
\beta(S E)\end{array}$ & $\begin{array}{l}\text { Model 1a } \\
\beta(\text { SE) }\end{array}$ & $\begin{array}{l}\text { Model 1b } \\
\beta(\mathrm{SE})\end{array}$ & $\begin{array}{l}\text { Model 1c } \\
\beta(\text { SE) }\end{array}$ & $\begin{array}{l}\text { Model 1d } \\
\beta(\text { SE) }\end{array}$ & $\begin{array}{l}\text { Model 1e } \\
\beta(\text { SE) }\end{array}$ & $\begin{array}{l}\text { Model 1f } \\
\beta(\text { SE) }\end{array}$ & $\begin{array}{l}\text { Model 1 } \mathbf{g} \\
\beta(\mathrm{SE})\end{array}$ & $\begin{array}{l}\text { Model } \\
1 \mathrm{~h} \\
\beta(\mathrm{SE})\end{array}$ \\
\hline $\begin{array}{l}\text { Total Annual } \\
\text { Precipitation (per } 1 \\
\text { SD increase) }\end{array}$ & $\begin{array}{l}0.07^{* *} \\
(0.01)\end{array}$ & $\begin{array}{l}0.07^{* *} \\
(0.02)\end{array}$ & $\begin{array}{l}0.07^{* *} \\
(0.02)\end{array}$ & $\begin{array}{l}0.06^{*} \\
(0.02)\end{array}$ & $\begin{array}{l}0.04^{*} \\
(0.02)\end{array}$ & $\begin{array}{l}0.07^{* *} \\
(0.01)\end{array}$ & $\begin{array}{l}0.06^{* *} \\
(0.02)\end{array}$ & $\begin{array}{l}0.06^{* *} \\
(0.02)\end{array}$ & $\begin{array}{l}0.07^{* *} \\
(0.02)\end{array}$ & $\begin{array}{l}0.07^{* *} \\
(0.02)\end{array}$ \\
\hline $\begin{array}{l}\text { Precipitation } \\
\text { Anomaly (per z- } \\
\text { score increase) }\end{array}$ & $\begin{array}{l}0.35 \\
(0.58)\end{array}$ & $\begin{array}{l}0.47 \\
(0.57)\end{array}$ & $\begin{array}{l}0.46 \\
(0.57)\end{array}$ & $\begin{array}{l}0.56 \\
(0.57)\end{array}$ & $\begin{array}{l}0.67 \\
(0.57)\end{array}$ & $\begin{array}{l}0.44 \\
(0.57)\end{array}$ & $\begin{array}{l}0.98 \\
(0.57)\end{array}$ & $\begin{array}{l}0.42 \\
(0.57)\end{array}$ & $\begin{array}{l}0.35 \\
(0.57)\end{array}$ & $\begin{array}{l}0.22 \\
(0.57)\end{array}$ \\
\hline
\end{tabular}

Model 1: adjusted for age and sex.

Model 1a: model 1+additional adjustment of sweet potatoes.

Model 1b: model 1+additional adjustment of groundnuts.

Model 1 c: model 1+additional adjustment of sesame seeds.

Model 1d: model 1+additional adjustment of chickpea.

Model 1e: model 1+additional adjustment of other pulses.

Model $1 \mathrm{f}$ : model $1+$ additional adjustment of rice.

Model $1 \mathrm{~g}$ : model 1+additional adjustment of maize.

Model 1h: model 1+additional adjustment of plantains.

${ }^{*} \mathrm{p}<0.05,{ }^{* *} \mathrm{p}<0.01$.

and tubers, seeds, and cash crops such as cotton and coffee (online supplementary table 2). Comparing the regression coefficients in model 1 , the regression coefficients in models $1 \mathrm{a}-1 \mathrm{e}$ were substantially decreased when controlling for groundnuts, pulses, sesame seeds and rice but no major change when adjusting for maize or plantains (model $1 \mathrm{~g}$ and $1 \mathrm{~h}$ ). For example, a $1 \mathrm{SD}$ increase in annual total precipitation was associated with a $43 \%$ decrease in HAZ (0.07 vs 0.04$)$ after adjusting for sesame seeds. The $\beta$ value between total annual precipitation and HAZ decreased by $14 \%$ (0.06 vs 0.07 ) after model adjustment with legumes such as groundnuts. This suggests that a notable proportion of the association between increased annual precipitation and HAZ can be explained by crop yield, especially from legumes, cereals and seeds, which are good sources of vitamins, minerals and proteins.

Because the most substantial attenuation in the regression coefficient after adjusting for the crop yield was observed in the association of annual precipitation with HAZ, we further performed causal mediation analysis to quantify the direct, mediation (indirect) and total effects of 1 SD increase in annual precipitation on HAZ. The results from these quantitative mediation analyses (direct, indirect and the $\%$ of the direct effect mediated) are presented in table 3 as the $\beta$ values, $95 \%$ CIs and $p$ values. Briefly, there was significant mediation effects from groundnuts, other pulses, sesame seeds, sweet potatoes and rice, whereas there remained a significant 'direct' effect between total annual precipitation and HAZ. In other words, annual precipitation was associated with HAZ, partially through the mediating of crop yield, whereas a significant amount of the association was through other factors, quantified as the 'direct' effect from these models.

\section{DISCUSSION}

We observed that increased total annual precipitation at the child's location, but not annual precipitation anomaly and aridity index, was associated with higher HAZ in a sample of children under-5 years in Uganda. Such an association could be partially attributed to excessive crop yield, especially legumes, grains, and cereals. These associations persisted after adjusting for major covariates, including age, gender and elevation. It indicated that low precipitation amount at a location is an independent risk factor for linear growth failure of children living in a country sustained by rainfed agriculture. Stunting has been identified as a risk factor to child mortality, and long-term neurocognitive outcomes. ${ }^{24-26}$ Our findings suggest that the spatial distribution of precipitation plays a critical role in local crop yield, which may eventually contribute to undernutrition risk.

\section{Aridity index and linear growth}

Although location aridity showed an association with linear growth in the unadjusted models, the relationship was eliminated after adjusting for elevation. Such an observation is consistent with previous studies that reported a lack of association between aridity index and child stunting in the multivariable-adjusted models, ${ }^{27}{ }^{28}$ but showed a strong positive linear relationship with high altitudes. ${ }^{29}{ }^{30} \mathrm{In}$ Uganda, children living near major mountains, Elgon and Rwenzori, are likely to be stunted, even though these areas are more humid compared with the low elevation regions. Therefore, the lower z-scores of linear growths at more humid locations revealed in our data were confounded by the high altitude. The exploration of factors explaining stunting at higher altitudes is beyond the scope of this study.

\section{Total precipitation and linear growth}

Many authors have reported significant associations between rainfall shocks and child mortality. ${ }^{31}{ }^{32}$ However, 
Table 3 Regression coefficients, 95\% Cls and p values in the association between 1 SD increase in annual precipitation total and height-for-age $z$ - scores from causal mediation models

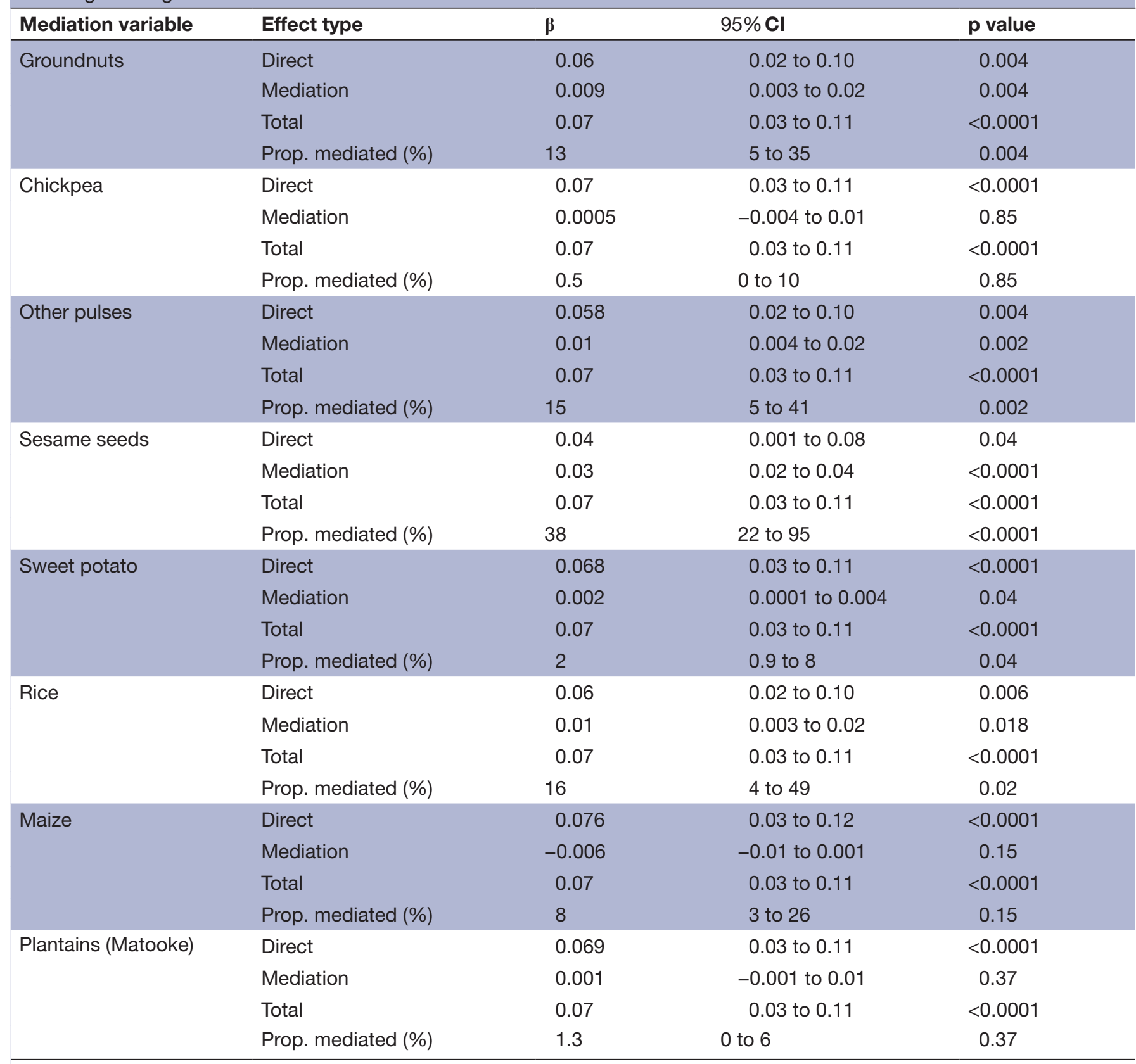

All models adjusted for age and sex.

the association of precipitation amount and spatial distribution with child growth, especially linear growth, is rarely investigated. Our key finding is the consistent positive association between village-level precipitation and linear growth measures, even after controlling for major covariates. Specifically, with a 1 SD increase in local precipitation, height-for-age z-scores increased by more than $6 \%$ of the HAZ (eg, $0.07 /-1.23 \mathrm{HAZ}$ ). Furthermore, only local annual rainfall amount, but not long-term rainfall anomaly, was significantly related to linear growth is suggestive of a more prominent role of annual rainfall level and distribution in the linear growth than that of a long-term anomaly in Uganda. We controlled for age and gender in all of our models; thus, our findings are independent of age-specific growth faltering observed between 6 months and 24 months, ${ }^{33}$ and the gender effect in which children who are male are differentially stunted in the subs-Saharan region. ${ }^{34}$ Stunting (length/ height-for-age z-score (HAZ) $\leq 2$ based on the WHO Child Growth Standards) is responsible for over $45 \%$ of under 5 mortality and impaired cognitive development ${ }^{24}$ and is associated with multiple risk factors, including fetal growth restriction, ${ }^{35}$ enteric and systemic infections, ${ }^{36}$ diarrhoeal diseases ${ }^{37}$ and poverty. The lack of an association between long-term rainfall anomaly and HAZ in Uganda could be explained by the fact that on average, 
Uganda has a higher precipitation amount due to its unique geographical location on the equator and presence of Lake Victoria and River Nile which runs south to north, transecting the country. ${ }^{11}$ The twice-a-year rainy peaks (March-May) and (September-November) help to buffer children from the deleterious nutritional effects of long-term precipitation shortfall. Our findings on the relationship between local annual precipitation amount and HAZ suggested a critical role of identifying areas that are most vulnerable to short-term rainfall failure so as to mitigate the risk of undernutrition, by introducing irrigation and climate shock-resistant crops.

\section{Mediating role of crop yield}

The mechanism linking climatic and weather variability and growth failure is unclear. Shively reported that an increase of $1 \mathrm{SD}$ in agricultural season rainfall was associated with a 0.05 - to 0.25 -point higher z-score, which translates into increases of roughly $4 \%-13 \%$ for HAZ. ${ }^{7}$ However, the nutrition sensitivity to rainfall was higher in countries where rainfall was lower on average and widerranging such as Nepal than in Uganda. In a more recently published study, Cooper et at reported that precipitation extremes and drought are associated with poor child nutrition outcomes, especially stunting. However, these studies did not explore the mediating effects of local agriculture crop yield in the association between rainfall and child nutrition outcomes. In Uganda, over $80 \%$ of the population depends on subsistence farming as a source of food for consumption, are predominantly rural farmers and their agricultural practices are predominantly rain-fed, characterised by low levels of crop productivity. ${ }^{38}$ Therefore, it can be hypothesised that rain-sensitive crop production and yields may mediate the relationship between precipitation and child nutrition outcomes. In this study, we attempted to investigate the mediating roles of crop yields in the precipitation and linear growth relationship using two methods. First, the mediating pathway of crop yield is supported by the substantial attenuation in the regression coefficients of precipitation in relation to linear growth measures, after entering the potential mediating factors such as legumes and grains. Second, we confirmed the above qualitative findings using the $\mathrm{R}$ package Mediation by quantifying the mediators' actual contribution and from the 'direct' effect. In general, although crop yield was identified as an essential mediating factor in our data, the precipitation and HAZ relationship cannot be fully explained by crop yield alone. Thus, there are other etiological pathways that we can only postulate. For instance, the availability of safe drinking water in most regions in sub-Saharan Africa is correlated with the availability of rainfall, lack of which can lead to the consumption of unhygienic water from unprotected well. Such practices contribute to diarrhoeal diseases and helminths all of which directly affects child nutrition outcomes. ${ }^{39}$

Like most Africans, Ugandans live on a diet based on one or more three staple food groups, namely cereals, roots or tubers and plantains with minimal or no protein of animal origin. ${ }^{40}{ }^{41}$ Some of the most widely consumed cereals in Uganda are maize, rice, sorghum and millet. Tubers include cassava and sweet potatoes. Although these staple foods are a great source of calories, they are devoid of proteins and essential amino acids. Our study reveals that the legumes (including pulses) and oilseeds were substantially associated with increased linear growth and were significant mediators of precipitation and linear growth. Pulses have relatively high levels of protein (20\%-40\%) and fibre (up to $20 \%$ ) compared with cereals, and low levels of fat (typically below 10\%) compared with oilseeds. ${ }^{42}$ These findings suggest advocacy for a plant-based source of proteins to mitigate malnutrition in countries that may not have access to the animal-based sources of proteins due to a lack of financial means. The mediator with a large effect size was sesame seeds. A nutritionally rich oilseed, sesame (Sesamum indicum L.) seed is a rich source of protein (18\%-25\%) and an excellent source of vegetable oil, having one of the highest oil contents $(35 \%-63 \%)$ among oil crops. ${ }^{43} 44$ The oils are monounsaturated and polyunsaturated, very stable due to the presence of several antioxidants such as sesamin, sesamolin, and sesamol. ${ }^{45}$ In East Africa, sesame is cultivated under rain-fed conditions, and increased oil accumulation correlates with precipitation. ${ }^{46}$ Besides, the seed is a valuable source of antibacterial activity against Staphylococcus and Streptococcus infections, indirectly mitigating infection-induced undernutrition. ${ }^{44}$

Approximately $80 \%$ of the study population lives in rural areas where subsistence level farming predominates. Although not explored, some of the nutritional effects of crop yield may stem from the increase in income generation and livelihood diversification. For example, Robusta coffee is a crucial cash crop which is universally adopted among smallholders farmers in different parts of the country. ${ }^{47}$ Income from agricultural economy may increase food diversification as households can now afford to buy nutritious foods, including animal products.

\section{Strengths and limitations}

Several strengths of this study are worth noting. First, we used remotely sensed crop yield data at a very fine spatial scale of $10 \mathrm{~km}$, closer to a village or a sub-county level in Uganda. We analysed 42 food and non-food crops and used rigorous statistical methods of LASSO to unbiasedly select variables that we used in the causal mediation regression analyses. Previous studies analysed districtlevel agriculture-related factors focusing on district-level mean staple food yield. ${ }^{7}$ District average precipitation and agricultural yield may not be the best indicator of average household water availability and food security due to a high degree of heterogeneity of both precipitation and agricultural practices. Furthermore, analysing district-level staple foods is not robust due to failure to capture diet diversity or essential nutrients in crop yield and consumption, which exist at a finer spatial resolution. 
In Uganda, staple food such as plantains (Matooke), cassava and millet are majorly starchy food lacking vital micronutrients and proteins. Therefore, it is not surprising that the regression coefficients of these foods were negative (0nline supplemental table 2), indicative of a negative association with HAZ. Second, we used NOAA-RFE 2.0 dataset to calculate annual precipitation and precipitation anomalies for 2010. RFE2 is a satellitebased product, is a robust product designed explicitly for operational climate monitoring for Africa. Other studies have used rain gauges to study rainfall in Uganda; however, these studies suffer from high biases in the measurements given the lack of adequate ground-based observations. ${ }^{12}$ Finally, we employed causal mediation models to quantify the mediating role of specific crop yield. This method enabled us to differentiate and quantify the mediation effects of crop yield and other sources ('direct' effect).

Our study also has some potential limitations. First, agriculture practices and rainfall amount at a spatial resolution lower than $10 \mathrm{~km}$ may better correlate with the induvial-level child growth. Currently, crop production and yield data at much finer spatial resolution are non-existent. Second, there is a strong filter between what is grown and what is fed to children under 5 . Food frequency questionnaires, 24 hours dietary recall and other appropriate tools should be used to elucidate child diets. Therefore, our findings should be interpreted with caution when drawing conclusions on the composition of child diets from the diversity of crops grown.

\section{CONCLUSION}

In conclusion, the findings from this study suggest that higher annual rainfall is significantly associated with linear growth, independent of elevation, age and gender. More importantly, this association can be partially explained by crop yields, especially legumes, seeds and grains. Our causal mediation modelling approach and output should be used to target interventions to children and to villages at highest risk of climate-driven undernutrition. However, to no small extent, the association cannot be explained by crop yield alone; thus, future studies that assess child diets or longitudinal instead of the current cross-section study design are needed to identify other mediating factors for such an association.

\section{Ethical considerations}

Written informed consent was obtained from each participant, their parents or guardians before the survey. The DHS programme permitted the authors to use the data. The data are entirely anonymous; therefore, the authors did not seek further ethical clearance.

Twitter Paddy Ssentongo @Jeddy 777

Acknowledgements We thank Measure DHS for permitting us to use nutritional data. We thank Anna Ssentongo for critical revisions of the manuscript and help with the figures.
Contributors PS envisioned the study, extracted data, analysed data, drafted the manuscript and made subsequent revisions. DMB, CF and VMC provided critical revisions to the manuscript.

Funding The authors have not declared a specific grant for this research from any funding agency in the public, commercial or not-for-profit sectors.

Competing interests None declared.

Patient and public involvement Patients and/or the public were not involved in the design, or conduct, or reporting, or dissemination plans of this research.

Patient consent for publication Not required.

Ethics approval The Uganda Demographic and Health Survey (UDHS) protocols and guidelines, including biomarker collection, were reviewed and approved by the Ugandan Ministry of Health $(\mathrm{MOH})$ Ethical Review Committee and the Institutional Review Board of ICF International, USA. All research and methods were performed per the regulations and guidelines of the Ugandan $\mathrm{MOH}$ and ICF International, USA Ethical Review Committee, and the Institutional Review Board, respectively.

Provenance and peer review Not commissioned; externally peer reviewed.

Data availability statement Data are available in a public, open access repository. The data sets were accessed after taking permission from Measure DHS. Data sets under the project Mapping Malnutrition in Children in Africa. The analysed dataset is available from: https://dhsprogram.com/data/dataset/Uganda_ Standard-DHS_2016.cfm?flag=1. Data are available for download from the website after acquiring permission from Measure DHS.

Open access This is an open access article distributed in accordance with the Creative Commons Attribution Non Commercial (CC BY-NC 4.0) license, which permits others to distribute, remix, adapt, build upon this work non-commercially, and license their derivative works on different terms, provided the original work is properly cited, appropriate credit is given, any changes made indicated, and the use is non-commercial. See: http://creativecommons.org/licenses/by-nc/4.0/.

ORCID iD

Paddy Ssentongo http://orcid.org/0000-0003-1565-5731

\section{REFERENCES}

1 World Health Organization. The state of food security and nutrition in the world 2018: building climate resilience for food security and nutrition: Food \& Agriculture Org; 2018.

2 United Nations Children's Fund (UNICEF), WHO. International bank for reconstruction and Development/The world bank. levels and trends in child malnutrition: key findings of the 2019 edition of the joint child malnutrition estimates, 2019. Available: https://www.who. int/nutgrowthdb/jme-2019-key-findings.pdf?ua=1

3 WHO Multicentre Growth Reference Study Group. Who child growth standards based on length/height, weight and age. Acta Paediatr Suppl 2006;450:76.

4 Ssentongo P, Ba DM, Ssentongo AE, et al. Association of vitamin A deficiency with early childhood stunting in Uganda: a populationbased cross-sectional study. PLoS One 2020;15:e0233615.

5 Ssentongo P, Ssentongo AE, DM B, et al. Pooled analysis of global, regional and country-level prevalence of childhood stunting, wasting and underweight in 62 Low-and middle-income countries, 20062018. Regional and Country-Level Prevalence of Childhood Stunting, Wasting and Underweight in 2019;62:2006-18.

6 Cooper MW, Brown ME, Hochrainer-Stigler S, et al. Mapping the effects of drought on child stunting. Proc Natl Acad Sci U S A 2019;116:17219-24.

7 Shively GE. Infrastructure mitigates the sensitivity of child growth to local agriculture and rainfall in Nepal and Uganda. Proc Natl Acad Sci U S A 2017;114:903-8.

8 Phalkey RK, Aranda-Jan C, Marx S, et al. Systematic review of current efforts to quantify the impacts of climate change on undernutrition. Proc Natl Acad Sci U S A 2015;112:E4522-9.

9 Belesova K, Agabiirwe CN, Zou M, et al. Drought exposure as a risk factor for child undernutrition in low- and middle-income countries: a systematic review and assessment of empirical evidence. Environ Int 2019;131:104973.

10 Field CB, Barros V, Stocker TF. Managing the risks of extreme events and disasters to advance climate change adaptation: special report of the intergovernmental panel on climate change Cambridge University Press; 2012.

11 Ssentongo P, Muwanguzi AJB, Eden U, et al. Changes in Ugandan climate rainfall at the village and forest level. Sci Rep 2018;8:3551. 
12 Maidment RI, Grimes DIF, Allan RP, et al. Evaluation of satellitebased and model Re-analysis rainfall estimates for Uganda. Meteorological Applications 2013;20:308-17.

13 Shively GE, Hao J. A review of agriculture, food security and human nutrition issues in Uganda 2012.

14 Uganda Bureau of Statistics U, Icf. Uganda demographic and health survey 2016. Kampala, Uganda UBOS and ICF; 2018.

15 Joglekar AKB, Wood-Sichra U, Pardey PG. Pixelating crop production: consequences of methodological choices. PLoS One 2019;14:e0212281.

16 NOAA C. The NOAA climate prediction center African rainfall estimation algorithm version 2.0; 2001

17 Arkin PA, Meisner BN. The relationship between large-scale convective rainfall and cold cloud over the Western hemisphere during 1982-84. Mon Weather Rev 1987:115:51-74.

18 Trabucco A, Zomer R. Global aridity index and potential evapotranspiration (ETO) climate database V2. figshare. Fileset 2019

19 Trabucco A, Zomer R. Global aridity index and potential EvapoTranspiration (ET0) climate database V2. CGIAR Consortium for spatial information (CGIAR-CSI) 2018.

20 Pearl J, Mackenzie D. The book of why: the new science of cause and effect. Basic Books, 2018.

21 Tibshirani R. Regression selection and shrinkage via the LASSO. J R Stat Soc Series B 1996;58:267-88.

22 Taylor J, Tibshirani RJ. Statistical learning and selective inference. Proc Natl Acad Sci U S A 2015;112:7629-34.

23 Tingley D, Yamamoto T, Hirose K, et al. Mediation: R package for causal mediation analysis 2014.

24 Black RE, Victora CG, Walker SP, et al. Maternal and child undernutrition and overweight in low-income and middle-income countries. Lancet 2013;382:427-51.

25 Christian P, Lee SE, Donahue Angel M, et al. Risk of childhood undernutrition related to small-for-gestational age and preterm birth in low- and middle-income countries. Int J Epidemiol 2013;42:1340-55.

26 Bryce J, Boschi-Pinto C, Shibuya K, et al. WHO estimates of the causes of death in children. Lancet 2005;365:1147-52.

27 Curtis SL, Hossain M. The effect of aridity zone on child nutritional status, West Africa spatial analysis prototype exploratory analysis. Calverton, Maryland: Macro International Inc, 1998.

28 Curtis SL, Hossain M. West Africa spatial analysis prototype exploratory analysis: the effect of aridity on child nutritional status. DHS spatial analysis reports no 2. Calverton, Maryland, USA: Macro International, 1998.

29 Dang S, Yan H, Yamamoto S, et al. Poor nutritional status of younger Tibetan children living at high altitudes. Eur J Clin Nutr 2004;58:938-46.

30 Harris NS, Crawford PB, Yangzom Y, et al. Nutritional and health status of Tibetan children living at high altitudes. N Engl J Med 2001;344:341-7.
31 Henry SJF, Dos Santos S. Rainfall variations and child mortality in the Sahel: results from a comparative event history analysis in Burkina Faso and Mali. Popul Environ 2013;34:431-59.

32 Pitt MM, Sigle W. Seasonality, weather shocks and the timing of births and child mortality in Senegal Brown University, Population Studies and Training Center Providence, Rl; 1998.

33 Victora CG, de Onis M, Hallal PC, et al. Worldwide timing of growth faltering: revisiting implications for interventions. Pediatrics 2010;125:e473-80.

34 Wamani H, Astrøm AN, Peterson S, et al. Boys are more stunted than girls in sub-Saharan Africa: a meta-analysis of 16 demographic and health surveys. BMC Pediatr 2007;7:17.

35 Victora CG, Villar J, Barros FC, et al. Anthropometric characterization of impaired fetal growth: risk factors for and prognosis of newborns with stunting or wasting. JAMA Pediatr 2015;169:e151431-e31.

36 Guerrant RL, DeBoer MD, Moore SR, et al. The impoverished gut--a triple burden of diarrhoea, stunting and chronic disease. Nat Rev Gastroenterol Hepatol 2013;10:220-9.

37 Guerrant RL, Oriá RB, Moore SR, et al. Malnutrition as an enteric infectious disease with long-term effects on child development. Nutr Rev 2008;66:487-505.

38 Turyahabwe N, Kakuru W, Tweheyo M, et al. Contribution of wetland resources to household food security in Uganda. Agric \& Food Secur 2013;2:5.

39 Schmidt CW. Beyond malnutrition: the role of sanitation in stunted growth: NLM-Export 2014.

40 Galati A, Oguntoyinbo FA, Moschetti G, et al. The cereal market and the role of fermentation in cereal-based food production in Africa. Food Reviews International 2014;30:317-37.

41 Temba MC, Njobeh PB, Adebo OA, et al. The role of compositing cereals with legumes to alleviate protein energy malnutrition in Africa. Int J Food Sci Technol 2016;51:543-54.

42 Gepts P, Beavis WD, Brummer EC, et al. Legumes as a model plant family. genomics for food and feed report of the cross-legume advances through genomics conference. Am Soc Plant Biol 2005.

43 Ashri A. Sesame breeding. Plant breeding reviews 1998;16:179-228.

44 Anilakumar KR, Pal A, Khanum F, et al. Nutritional, medicinal and industrial uses of sesame (Sesamum indicum L.) seeds-an overview. Agriculturae Conspectus Scientificus 2010;75:159-68.

45 Suja KP, Abraham JT, Thamizh SN, et al. Antioxidant efficacy of sesame cake extract in vegetable oil protection. Food Chem 2004;84:393-400.

46 Were BA, Onkware AO, Gudu S, et al. Seed oil content and fatty acid composition in East African sesame (Sesamum indicum L.) accessions evaluated over 3 years. Field Crops Res 2006;97:254-60.

47 de Haas M. Measuring rural welfare in colonial Africa: did Uganda's smallholders thrive? Econ Hist Rev 2017;70:605-31. 